\title{
ИННОВАЦИОННЫЕ МЕТОДЫ ФИНАНСИРОВАНИЯ ПРОМЫШЛЕННОГО ПРОИЗВОДСТВА В КОНТЕКСТЕ КОНЦЕПЦИИ УСТОЙЧИВОГО РАЗВИТИЯ
}

\author{
(C) 2020 Малевская-Малевич Екатерина Данииловна \\ кандидат экономических наук, доцент Высшей инженерно-экономической школы \\ Санкт-Петербургский политехнический университет Петра Великого, Россия, Санкт-Петербург \\ E-mail: malevskaia@spbstu.ru
}

Переход к концепции устойчивого развития является одним из приоритетных направлений комплексного развития Российской экономики. Безусловно, устойчивое развитие - тема обширная, поэтому подробно мы рассмотрим понятие осознанных инвестиций, под которыми принято понимать вложение средств в такие ценные бумаги, как «зеленые» облигации. Такие ценные бумаги созданы для финансирования проектов, имеющих положительные экологические и / или климатические преимущества. Существует ряд принципов, которым должен соответствовать эмитент или проект, для финансирования которого они выпускаются, соблюдение которых является необходимым условием для эмиссии «зеленых» облигаций. Тренд устойчивого развития предполагает долгосрочную стратегию, обеспечивающую сохранение ограниченных природных ресурсов для будущих поколений, осознанное отношение к производству, потреблению, а также их последствиям для окружающей среды. На данный момент существует целый ряд современных источников финансирования, учитывающих специфический характер инновационной деятельности, сопряженной с высокими рисками и неопределёнными сроками окупаемости. Несмотря на отмеченную специфику и относительную новизну данного источника финансирования объемы выпуска «зеленых» облигаций показывают постоянный рост и имеют перспективы опережающего восстановления докризисного объема по сравнению с традиционными финансовыми инструментами. Причина такого тренда в нарастающем интересе к осознанному инвестированию. В статье дано определение термина «зеленые облигации», проведен анализ объема мирового выпуска данных ценных бумаг, а также опыта российских предприятий, определены основные риски эмитента и инвестора, приведена сравнительная характеристика возможных вариантов выпуска «зеленых» облигаций. Определены принципы формирования стоимости «зеленых» облигаций как источника капитала предприятия, определены его потенциальные преимущества в сравнении с традиционными источниками финансирования, такими как облигации, банковское кредитование. Целью исследования является анализ потенциального инновационного источника финансирования деятельности промышленных предприятий России, а именно выпуска «зеленых» облигаций. Объектом исследования является специфический вид ценных бумаг - «зеленые» облигации. Предмет исследования - инновационные методы финансирования промышленного производства в контексте концепции устойчивого развития.

Ключевые слова: устойчивое развитие промышленных предприятий, инновационный продукт, особенности финансирования, зеленые облигации.

\section{Введение}

В принципе проблема привлечения долгосрочного финансирования является весьма актуальной для промышленных предприятий России, так как традиционно любая инновационная деятельность сопряжена с большими рисками и долгими сроками окупаемости, что значительно снижает круг потенциальных инвесторов. Одним из инструментов долгосрочного заемного финансирования, сочетающим в себе приемлемую доходность для инвестора, ограниченный риск инвестора, относительно невысокую стои- мость капитала для эмитента, является облигация. В настоящее время получили распространение так называемые «зеленые» облигации, такой вид инвестирования также называют «осознанным». Рассмотрим предпосылки возникновения этого источника финансирования $[8,14]$.

Так называемые «зеленые» облигации сравнительно новый источник финансирования. Такие ценные бумаги были созданы для финансирования проектов, имеющих положительные экологические и / или климатические преимущества. Большинство выпущенных зеленых 
облигаций - это зеленые облигации с «использованием поступлений» или облигации, привязанные к активам. Поступления от этих облигаций предназначены для финансирования «зеленых» инвестиционных проектов. Эмитентами облигаций могут быть муниципалитеты, инвестиционные банки, предприятия, покупателями- как институциональные, так и частные инвесторы $[12,13]$.

Рынок зеленых облигаций продемонстрировал сильный рост, причем рынок действительно начал расти в 2014 году, когда было выпущено 37 миллиардов долларов. В 2018 году эмиссия достигла 167,3 млрд. долларов США, что стало еще одним рекордом.

Рынок зеленых облигаций стартовал в 2007 году с выпуска Европейского инвестиционного банка (ЕИБ) и Всемирного банка - с рейтингом ААА. В 2014 году на рынке произошел поворотный момент, когда была выпущена первая корпоративная зеленая облигация Vasakronan, шведской компании, занимающейся недвижимостью $[15,16]$.

По данным инвестиционной компании «ФИНАМ», согласно еженедельному мониторингу рынка еврооблигаций от 19 октября 2020 г. в сегменте выпуска еврооблигаций можно отметить выпуск ОАО «РЖД» с погашением в 2027 г. Как и другие еврооблигации в единой европейской валюте, этот выпуск показал отрицательную динамику в следствии пандемии, однако, аналитики положительно оценивают перспективы его восстановления, связывая их не только с общим трендом рынка - сокращением кредитных спредов заемщиков из ЕМ по мере нормализации ситуации в мировой экономике, но прежде всего с тем, что данный евробонд является «зеленым» выпуском. Этот выпуск стал первым green bond, размещенным российской компанией на внешнем рынке. Данный сегмент облигационного рынка является одним из самых быстрорастущих в мире, спрос на такие бумаги формируют так называемые ESG-фонды (Environmental, Social и Governance). Отметим, что Euro Green Bond Index (отслеживающий номинированные в единой европейской валюте «зеленые» евробонды) буквально на днях преодолел последствия текущего кризиса, переписав свои исторические максимумы. Следует отметить, что компания РжД уже имеет опыт выпуска «зеленых» облигаций, так, ранее компания разместила на рынке уникальный и абсолютно инновационный дол- говой инструмент - бессрочный «зеленый» выпуск рублевых облигаций с плавающей ставкой купона. Это было первое рыночное размещение «зеленых» облигаций в России для государственного корпоративного заемщика с наивысшим кредитным качеством. Объем выпуска в ходе размещения был увеличен с изначально заявленных 20 млрд. руб. до 100 млрд. руб. [10,17]

Очевидно, что объем рынка «зеленых» облигаций увеличивается, что говорит о необходимости проработки теоретической и методологической базы для определения методов ценообразования этих финансовых инструментов, а также определения эффективности их использования в качестве источника финансирования инновационной деятельности предприятий, что и послужило целью данного исследования [1,2].

\section{Результаты исследования}

По результатам проведенного анализа можно сгруппировать возможные варианты выпуска «зеленых» облигаций в таблицу 1.

Безусловно, «зеленые», эколого-ориентированные проекты, являются инвестиции с повышенной рисковой надбавкой, длительным сроком окупаемости и, как правило, с очень низкой доходностью. Однако, у данного инструмента есть неоспоримые преимущества $[3,4,9]$.

Во-первых, выпуск бессрочных облигаций позволяет компаниям привлекать капитал, который отражается как собственный в структуре пассива баланса предприятия. Учитывая текущее нестабильное состояние экономики это позволит повысить финансовую устойчивость предприятия, снизить вероятность банкротства, что в свою очередь приведет к снижению общей стоимости капитала компании $[5,10]$.

Во-вторых, как было отмечено ранее, в стоимость таких ценных бумаг аналитики закладывают так называемый «потенциал роста», или PVGO (Present Value of Growth Opportunities), показать, который принято рассчитывать, как составляющая приведенной стоимости акций, однако, на взгляд авторов, в контексте «зелёных» облигаций он также может быть включен, как составная часть стоимости. Это связано в первую очередь с репутационным фактором, так как «зеленое» инвестирование сегодня является наиболее актуальным трендом на мировых рынках $[6,7,8]$.

B-третьих, компенсацией за повышенный 
Таблиц̧а 1.

\begin{tabular}{|c|c|c|c|}
\hline Вид & $\begin{array}{c}\text { Доходы от продажи } \\
\text { облигаций }\end{array}$ & Гарантия долга & Пример \\
\hline $\begin{array}{l}\text { Облигация «с использова- } \\
\text { нием поступлений» }\end{array}$ & $\begin{array}{l}\text { Предназначены для фи- } \\
\text { нансирования «зеленых» } \\
\text { проектов }\end{array}$ & $\begin{array}{l}\text { Долг гарантирует эми- } \\
\text { тент: применяется тот } \\
\text { же кредитный рейтинг, } \\
\text { что и у других облигаций } \\
\text { эмитента. }\end{array}$ & $\begin{array}{l}\text { EIB «Climate Awareness } \\
\text { Bond» (backed by EIB); } \\
\text { Barclays Green Bond }\end{array}$ \\
\hline $\begin{array}{l}\text { Облигация «с использова- } \\
\text { нием поступлений» или } \\
\text { ABS }\end{array}$ & $\begin{array}{l}\text { Предназначены для ре- } \\
\text { финансирования зеленых } \\
\text { проектов }\end{array}$ & $\begin{array}{l}\text { Чистый денежный поток } \\
\text { эмитента за вычетом } \\
\text { процентов и налогов яв- } \\
\text { ляется залогом по долгу. }\end{array}$ & $\begin{array}{l}\text { Hawaii State (backed by fee } \\
\text { on electricity bills of the } \\
\text { state utilities) }\end{array}$ \\
\hline Проектные облигации & $\begin{array}{l}\text { Предназначены для фи- } \\
\text { нансирования конкрет- } \\
\text { ного «зеленого» проекта, } \\
\text { являющегося обеспече- } \\
\text { нием для облигации }\end{array}$ & $\begin{array}{l}\text { Обеспечением служит } \\
\text { залоговый актив, или в } \\
\text { данном случае «зеленый» } \\
\text { проект. }\end{array}$ & $\begin{array}{l}\text { Invenergy Wind Farm } \\
\text { (backed by Invenergy } \\
\text { Campo Palomas wind farm) }\end{array}$ \\
\hline $\begin{array}{l}\text { Секьюритизация (ABS) } \\
\text { облигаций }\end{array}$ & $\begin{array}{l}\text { Портфели рефинансиро- } \\
\text { вания зеленых проектов }\end{array}$ & $\begin{array}{l}\text { С залогом фондовых } \\
\text { бумаг - обеспечение цен- } \\
\text { ными бумагами другой } \\
\text { компании, находящимися } \\
\text { в собственности эми- } \\
\text { тента (например, аренда } \\
\text { солнечных батарей или } \\
\text { зеленая ипотека) }\end{array}$ & $\begin{array}{l}\text { Tesla Energy (backed by } \\
\text { residential solar leases); } \\
\text { Obvion (backed by green } \\
\text { mortgages) }\end{array}$ \\
\hline $\begin{array}{l}\text { обеспеченная облигация } \\
\text { (С залогом пула заклад- } \\
\text { ных) }\end{array}$ & $\begin{array}{l}\text { Предназначен для прием- } \\
\text { лемых проектов, вклю- } \\
\text { ченных в крытый пул }\end{array}$ & $\begin{array}{l}\text { Выпуск таких облигаций } \\
\text { осуществляется кредито- } \\
\text { ром, который имеет пул } \\
\text { ипотек под выданные } \\
\text { ссуды под недвижимость. } \\
\text { Платежи, поступившие } \\
\text { по ссудам, - источник } \\
\text { погашения и выплаты } \\
\text { процентов по облигаци- } \\
\text { онному займу. }\end{array}$ & $\begin{array}{l}\text { Berlin Hyp green } \\
\text { Pfandbrief; Sparebank } 1 \\
\text { Bolligkredit green covered } \\
\text { bond }\end{array}$ \\
\hline
\end{tabular}

риск инвестора может служить приращение показателя Goodwill, то есть деловой репутации компании, показателя, который не присутствует в российском бухгалтерском учета, а в МСФО это специфический вид нематериальных активов, который нельзя оценить напрямую. Тем не менее доказано, что именно так называемые «нераскрытые» нематериальные активы генерируют основную рыночную стоимость компании в условиях цифровой экономики. В виду того, что все эколого-ориентированные проекты сегодня воспринимаются на рынке как крайне положительные, можно утверждать, что при равной эффективности они «выиграют» у «обычных» проектов именно за счет улучшения деловой репутации как эмитента, так и инвестора.

Выделяют два вида Гудвилла:

Приобретенный гудвилл - это разница между стоимостью, уплачиваемой за предприятие как непрерывно действующее, и суммой его активов за вычетом суммы его обязательств, каждая из которых была идентифицирована и оценена отдельно.

Неотъемлемый: это стоимость бизнеса, превышающая справедливую стоимость его разделяемых чистых активов. Это называется гудвиллом, созданным внутри компании, и возникает в течение определенного периода времени из-за хорошей репутации компании. Его также можно назвать гудвиллом, созданным самостоятельно или не приобретенным.

Именно ко второму виду гудвилла можно отнести положительный репутационный эффект от выпуска «зеленых» инноваций, который не только увеличивает рыночную стоимость компании, но и повышает ее инвестиционную привлекательность для иностранных инвесторов.

\section{Заключение}

Таким образом, «зеленые» облигации являются одним из основных источников финансирования «зеленых» инноваций, но методы оценки «зеленых» проектов и рисков являются такими же, как при традиционном финанси- 
ровании. Безусловно, на сегодняшний день это источник финансирования доступен только институциональным игрокам и крупным корпорациям. В связи с длительной окупаемостью, а также недостаточным развитием данный финансовый инструмент является не таким привлекательным для частных инвесторов, в результате чего требуется государственная поддержка. Российские инвесторы заинтересованы в максимизации своего благосостояния, и как следствие, инвестируют в наиболее доходные финансовые инструменты. Соответственно, в России «зеленое» финансирование нуждается в дальнейшем развитии, в связи с чем необходимо создавать благоприятную инфраструктуру как для потенциальных эмитентов «зеленых» финансовых инструментов, так и потенциальных инвесторов, а также разрабатывать нормативно-правовую базу, направленную на развитие данной экономической области.

\section{Библиографический список}

1. Бабкин А.В., Алексеева Н.С. Тенденции развития цифровой экономики на основе исследования наукометрических баз данных //Экономика и управление. - 2019. - № . 6. - С. 16-25.

2. Бабкин А.В., Кунин В.А., Тарутько О.А. Влияние цифровизации экономики на конкурентоспособность предпринимательских структур //Экономика и управление. - 2019. - № . 10. - С. 65-73.

3. Безсмертная Е.Р. «ЗЕЛЕНЫЕ» ФИНАНСОВЫЕ ИННОВАЦИИ: НАПРАВЛЕНИЯ И ПЕРСПЕКТИВЫ РАЗВИТИЯ // Феномен рыночного хозяйства: от истоков до наших дней. Партнерство в условиях риска и неопределенности.-2020.- С. 290-298.

4. Боркова Е.А. Политика устойчивого развития и управление «зеленым» ростом //Известия СанктПетербургского государственного экономического университета. - 2020. - № . 1 (121).

5. Вертакова Ю.В., Головина Т.А., Полянин А.В. Управление бизнес-процессами интегрированных структур на принципах совместного использования цифровых технологий //Научно-технические ведомости СанктПетербургского государственного политехнического университета. Экономические науки. - 2019. - Т. 12.№ . 4 .

6. Демиденко Д. С. Цифровая экономическая модель инновационного предприятия. -2020.

7. Демиденко Д. С. Особенности экономического анализа эффективности инновационных процессов на предприятии //Форсайт «Россия»: будущее технологий, экономики и человека.-2019.- С. 608-616.

8. ДОРОФЕЕВ М. Л. Особенности стоимости капитала на рынке зеленых облигаций //ЭКО.-2020. - № . 5. - С. 62-76.

9. Заручникова Н. О., Глухов В.В. Системауправления интеллектуальным капиталом научно-производственных организаций и кластеров в условиях цифровой трансформации экономики //Научно-технические ведомости Санкт-Петербургского государственного политехнического университета. Экономические науки.2019.- Т. 12.- № . 6 .

10. Макаров В.В., Шувал-Сергеева Н. С. Выбор источника финансирования инновации на разных этапах ее жизненного цикла: объем финансирования и качество инновации //Вопросы радиоэлектроники. - 2019. - № . 1.- C. $78-80$.

11. Макаров В.В., Старкова Т.Н., Устриков Н.К. Цифровая экономика: эволюция, со стояние и резервы развития //Журнал правовых и экономических исследований. - 2019. - № . 4. - С. 222-229.

12. Рубцов Б.Б., Анненская Н.Е. «Зеленые» облигации-особый инструмент в создании дорожной карты» зеленых» финансов (мнение экспертов Финансового университета) //Банковские услуги. - 2019. - № . 11. - С. $2-9$.

13. Хмыз О.В. Международный опыт выпуска» зеленых» облигаций //Экономика. Налоги. Право. - 2019.- Т. 12.- №. 5 .

14. Zerbib O.D. The effect of pro-environmental preferences on bond prices: Evidence from green bonds //Journal of Banking \& Finance. - 2019.- T. 98.- C. 39-60.

15. Banga J. The green bond market: a potential source of climate finance for developing countries //Journal of Sustainable Finance \& Investment. - 2019.- T. 9. - № . 1.- C. 17-32.

16. Tang D.Y., Zhang Y. Do shareholders benefit from green bonds? //Journal of Corporate Finance. - 2020. - T. 61.- C. 101427.

17. Данные сайта https://bonds.finam.ru/. Дата обращения - 18.10.2020 